\title{
PENEIRAS DE ALTA FREQUENCIA NO BENEFICIAMENTO MINERAL*
}

\author{
Gustavo Queiroz Esteves ${ }^{1}$ \\ Marco Túlio Sá Cabra² \\ Ricardo Mazon ${ }^{3}$ \\ Wanderson Jesus ${ }^{4}$
}

\section{Resumo}

O objetivo deste trabalho foi avaliar a utilização de peneiras de alta frequência em circuitos de beneficiamento mineral. Foram testadas diferentes aberturas de telas $(\mathrm{mm})$, taxa de alimentação (t/h) e percentual de sólidos para verificar a eficiência global de peneiramento na fração $0.15 \mathrm{~mm}$. Frações retidas nesta malha têm sido apontadas como críticas para a flotação, sobretudo flotação em colunas. O circuito clássico das usinas normalmente utiliza ciclones para classificação de partículas finas $(<1 \mathrm{~mm})$ e assim a peneira de alta frequência surge como uma alternativa frente a este equipamento.

Palavras-chave: Flotação; partículas grosseiras; Peneiras de alta frequência.

\section{Abstract}

HIGH FREQUENCY SCREENS IN MINERAL PROCESSING

The aim of this study was to evaluate the use of high-frequency screens in mineral processing circuits. Different screen openings $(\mathrm{mm})$, feed rate $(\mathrm{t} / \mathrm{h})$ and solids content were tested to verify the overall efficiency of screening in the fraction $0.15 \mathrm{~mm}$. Fractions retained in this mesh have been identified as critical for flotation, especially columns flotation. The classic circuit of plants typically utilizes cyclones for classification of fine particles $(<1 \mathrm{~mm})$ and high-frequency screen appears as an alternative front of these equipment.

Keywords: Flotation; Coarse particles; High frequency screens.

1 Engenheiro de Minas Sênior, Equipe de Prontidão Operacional, Vale, Itabira, MG, Brasil.

2 Técnico em Mineração, Implantação e Comissionamento, PROGEN, Itabira, MG, Brasil.

3 Engenheiro de Minas Master, MSc, Departamento de Tratamento de Minérios Cauê, Vale, Itabira. MG, Brasil.

4 Engenheiro Metalurgista, Suporte Técnico Operacional, Vale, Itabira, MG, Brasil.

* Contribuição técnica ao $44^{\circ}$ Seminário de Redução de Minério de Ferro e Matérias-primas, 15ํ Simpósio Brasileiro de Minério de Ferro e $2^{\circ}$ Simpósio Brasileiro de Aglomeração de Minério de Ferro, 15 a 18 de setembro de 2014, Belo Horizonte, MG, Brasil. 


\section{INTRODUÇÃO}

No beneficiamento mineral, a operação unitária de classificação corresponde à separação de uma população de partículas em diferentes classes de tamanho, em geral duas, sendo uma com grande proporção de partículas maiores e a outra de partículas proporcionalmente menores, conforme Chaves [6].

De acordo com Masini [8], durante muito tempo esta etapa foi realizada por classificadores mecânicos, posteriormente sendo substituídos por hidrociclones ou simplesmente ciclones. Atualmente, os principais equipamentos utilizados para classificação são os classificadores helicoidais, também conhecidos como classificadores "espirais", peneiras e ciclones.

Apesar dos projetos de ciclones continuarem evoluindo, este equipamento apresenta eficiência de separação da ordem de 45 a 65\%, cita Albuquerque et al [2]. Em consequência disto, surgiu-se a necessidade de trabalhar em outros métodos que pudessem vir a elevar esta eficiência de classificação, principalmente em partículas finas $(<1 \mathrm{~mm})$;

Em 2009, Albuquerque et al [3], realizaram testes substituindo ciclones por peneiras de alta frequência em fechamento de circuitos de moagem e concluíram que o aumento de eficiência na etapa de classificação reduziu em torno de 55\% a carga circulante, melhorando a eficiência do processo e promovendo ganhos em produtividade.

O presente estudo apresentará resultados obtidos através de testes realizados com peneiras de alta frequência, como alternativa de classificação de minérios na fração $0.15 \mathrm{~mm}$, onde o escalpe desta fração da alimentação da flotação foi o principal objetivo.

Segundo Vieira [9], o tamanho da partícula é importante no âmbito da hidrodinâmica da polpa, pois a influência da granulometria das partículas minerais processo de flotação sempre foi estudada e ainda é bastante discutida. Sabe-que, sem dúvida alguma, esse é um parâmetro extremamente importante para o sucesso do processo de flotação.

Para Amorim [4], partículas que passam pelo processo de flotação precisam estar em uma faixa granulométrica ideal para apresentarem boas recuperações e teores. Esta faixa ideal depende do mineral que será flotado, já que os minerais não têm características mineralógicas iguais. No exemplo da flotação de minério de ferro, a faixa ideal estava abaixo de $0.15 \mathrm{~mm}$.

Outros autores como Ahmed e Jameson [1] e Hermaniz e Calero [7] mostram que o tamanho de partículas minerais envolvidos no processo pode afetar a taxa de flotação. Para o caso da flotação reversa de minério de ferro, onde a distribuição da sílica nas várias frações não é homogênea, esse efeito pode ser mais acentuado, relata Carvalho e Martins [5].

\section{MATERIAIS E MÉTODOS}

A primeira etapa do trabalho foi feita em escala laboratorial, onde vários ensaios foram realizados para avaliar os seguintes parâmetros: malha de abertura $(\mathrm{mm})$, percentual de sólidos e densidade de trabalho do material que será alimentado na peneira.

\footnotetext{
* Contribuição técnica ao $44^{\circ}$ Seminário de Redução de Minério de Ferro e Matérias-primas, 15은 Simpósio Brasileiro de Minério de Ferro e $2^{\circ}$ Simpósio Brasileiro de Aglomeração de Minério de Ferro, 15 a 18 de setembro de 2014, Belo Horizonte, MG, Brasil.
} 
Durante a execução dos ensaios trabalhou-se com amostra de minério de ferro cuja distribuição granulométrica e análise química estão apresentadas nas tabelas 1 e 2, respectivamente.

Tabela 1: Distribuição granulométrica do material utilizado nos testes

\begin{tabular}{|l|c|c|c|c|c|c|}
\hline Aberturas [mm] & 0,25 & 0,15 & 0,106 & 0,075 & 0,045 & Fundo \\
\hline Retido Simples [mm] & 3 & 4,33 & 15,43 & 20,64 & 34,9 & 21,7 \\
\hline Retido Acumulado [mm] & 3 & 7,33 & 22,76 & 43,4 & 78,3 & 100 \\
\hline
\end{tabular}

Tabela 2: Análise química da amostra [\%]

\begin{tabular}{|c|c|c|c|c|c|c|c|}
\hline $\mathrm{Fe}$ & $\mathrm{SiO} 2$ & $\mathrm{P}$ & $\mathrm{Al}_{2} \mathrm{O}_{3}$ & $\mathrm{Mn}$ & $\mathrm{TiO}_{2}$ & $\mathrm{CaO}$ & $\mathrm{MgO}$ \\
\hline 59,92 & 13,24 & 0,009 & 0,220 & 0,041 & 0,051 & 0,013 & 0,041 \\
\hline
\end{tabular}

O equipamento utilizado foi a peneira de alta frequência modelo StackSizer, fabricada pela companhia Derrick e ilustrada na figura 1

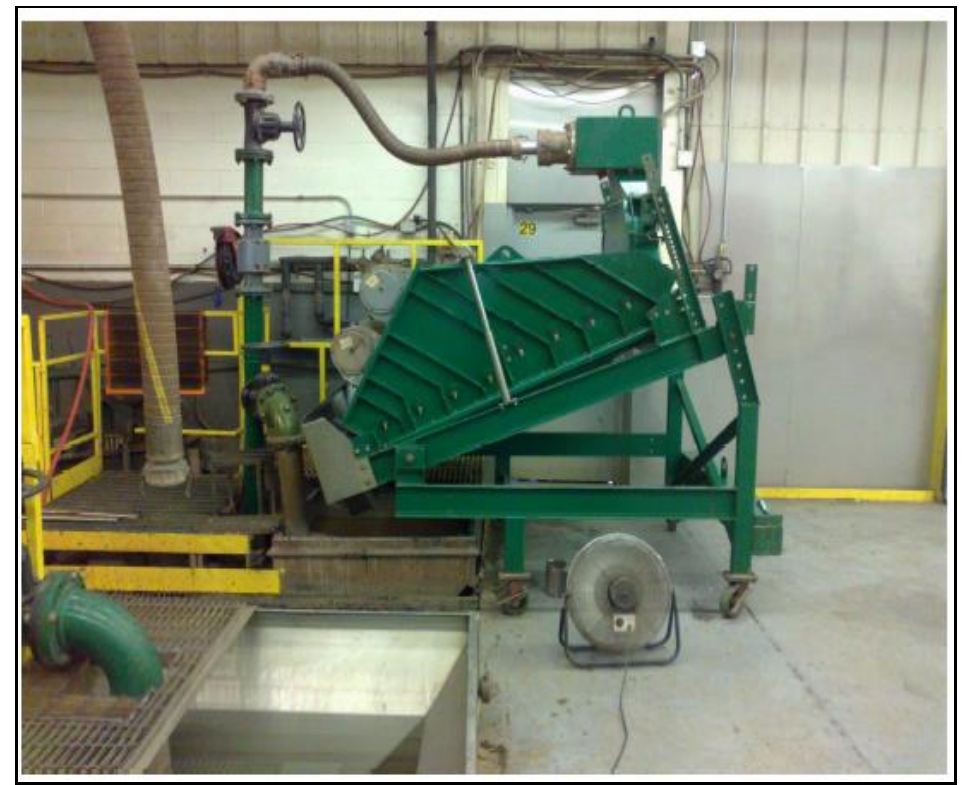

Figura 1: Peneira de alta frequência modelo StackSizer da Companhia Derrick

Para iniciar os testes era necessário ajustar a densidade da polpa conforme o seguinte procedimento: adicionava-se água à caixa da bomba e ligava-se, a seguir, a mesma.

Transferia-se parte da amostra de minério de ferro para a caixa e após alguns minutos de agitação da polpa, uma alíquota é retirada para verificar a densidade. Este processo é repetido várias vezes, até que a densidade de polpa atinja o valor desejado.

Uma amostra da alimentação é secada, para se confirmar a densidade da alimentação. Como os testes são executados em circuito fechado, após a coleta das amostras.

A vazão de cada teste é ajustada para o valor desejado com auxílio de uma válvula pinch.

\footnotetext{
* Contribuição técnica ao 44ํ Seminário de Redução de Minério de Ferro e Matérias-primas, 15ํ Simpósio Brasileiro de Minério de Ferro e $2^{\circ}$ Simpósio Brasileiro de Aglomeração de Minério de Ferro, 15 a 18 de setembro de 2014, Belo Horizonte, MG, Brasil.
} 
A figura 2 ilustra o circuito em que os testes serão conduzidos para determinar o efeito das seguintes variáveis: abertura da malha $(\mathrm{mm})$, taxa de alimentação $(\mathrm{t} / \mathrm{h})$ e percentual de sólidos.

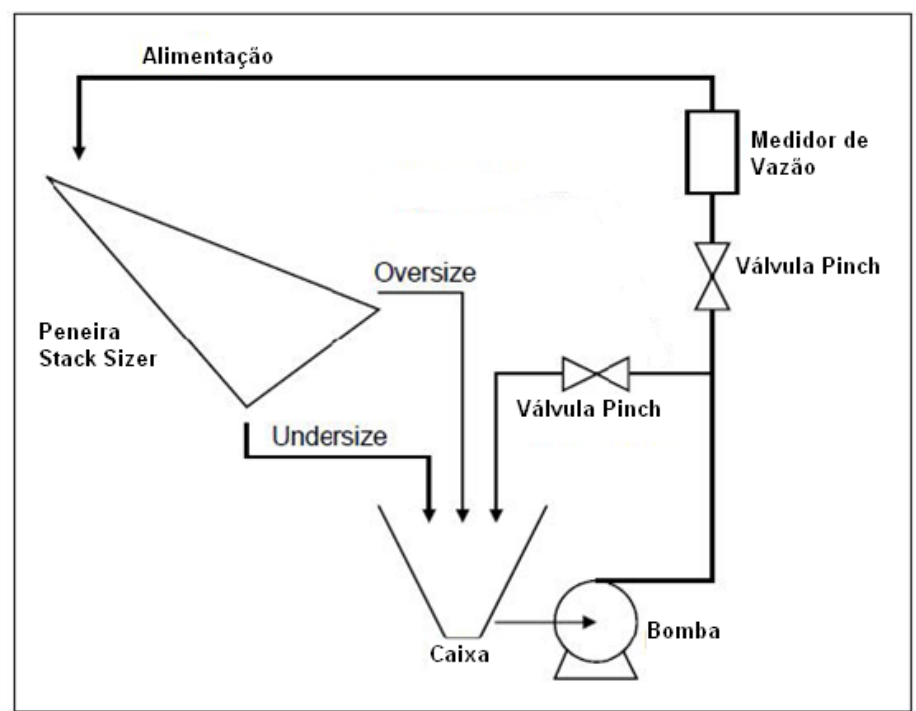

Figura 2: Circuito fechado de testes em escala laboratorial

Para cada teste amostrava-se o retido e o passante e se necessário o fluxo de alimentação, a partir daí faz-se então os cálculos de eficiência de peneiramento. A eficiência do peneiramento é calculada a partir da distribuição granulométrica da alimentação e dos produtos. As equações de 1 a 5 foram utilizadas nos cálculos.

$$
\begin{array}{r}
\mathrm{U}=\text { massa de undersize }(\%)=100(\mathrm{C}-\mathrm{A}) / \mathrm{C}+\mathrm{D}-100(1) \\
\mathrm{O}=\text { massa de oversize }(\%)=100-\mathrm{U}(2) \\
\text { Eu }=\text { eficiência de undersize }=(\mathrm{UD}) / \mathrm{B}(3) \\
\mathrm{E}=\text { eficiência do oversize }=(\mathrm{OC}) / \mathrm{A}(4) \\
\mathrm{E}=\text { eficiência global }=(\mathrm{UD}+\mathrm{OC}) / 100(5)
\end{array}
$$

Onde: $A=$ percentual de grossos na alimentação

$$
\begin{aligned}
& B=\text { percentual de finos na alimentação }(100-\mathrm{A}) \\
& \mathrm{C}=\text { percentual de partícula grosseira no oversize } \\
& D=\text { percentual de partículas finas no undersize }
\end{aligned}
$$

Em escala industrial foram utilizadas oito peneiras, instaladas antes da flotação em colunas. Optou-se por trabalhar com telas de $0.18 \mathrm{~mm}$, taxa de alimentação em $100 t / h$ e $40 \%$ de sólidos na alimentação de cada peneira.

A figura 3 ilustra o circuito proposto para os testes industriais.

* Contribuição técnica ao 44 Seminário de Redução de Minério de Ferro e Matérias-primas, 15오 Simpósio Brasileiro de Minério de Ferro e 2ํ Simpósio Brasileiro de Aglomeração de Minério de Ferro, 15 a 18 de setembro de 2014, Belo Horizonte, MG, Brasil. 


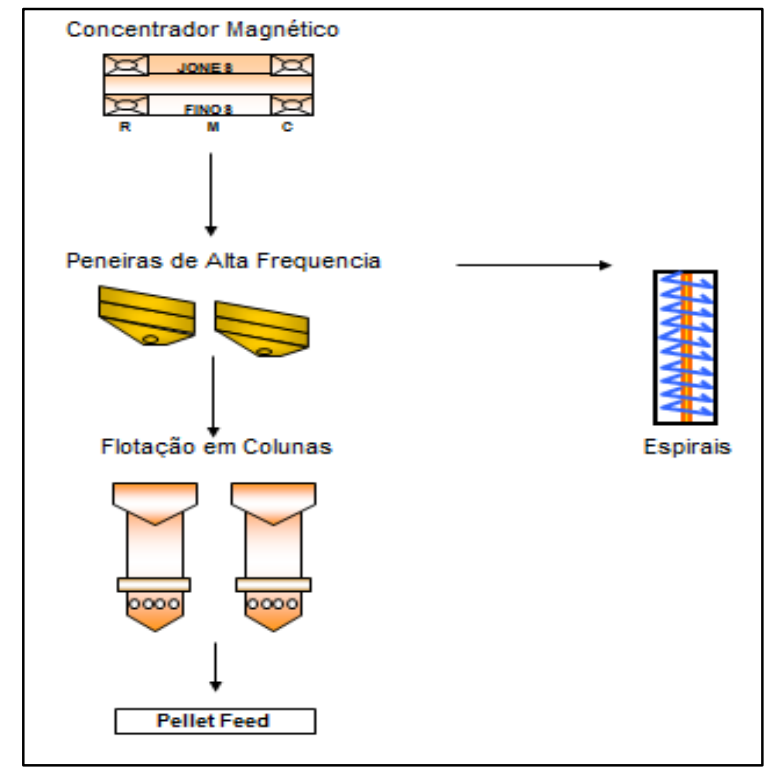

Figura 3: Circuito proposto nos testes industriais

\section{RESULTADOS E DISCUSSÃO}

Na primeira etapa foram testadas duas aberturas de tela 0.15 e $0.18 \mathrm{~mm}$. Além disto, variou-se a taxa de alimentação para cada ensaio em 100 e 120 t/h.

Outro fator avaliado foi o percentual de sólidos da alimentação, onde trabalhou-se com 40,45 e $50 \%$ de sólidos.

A tabela 3 apresenta os resultados obtidos nos testes realizados com as telas de $0.15 \mathrm{~mm}$ para 100 e $120 \mathrm{t} / \mathrm{h}$, com percentuais de sólidos em 40, 45 e 50\%.

Tabela 3: Alimentação, oversize e undersize obtidos nos testes com telas de $0.15 \mathrm{~mm}$

\begin{tabular}{|c|c|c|c|c|c|c|c|c|c|}
\hline \multicolumn{4}{|c|}{ Alimentação } & \multicolumn{3}{|c|}{ Oversize } & \multicolumn{3}{|c|}{ Undersize } \\
\hline Vazão (m3/h) & Massa $(t / h)$ & Sólidos (\%) & $+0.15 \mathrm{~mm}(\%)$ & Massa (\%) & Sólidos (\%) & $+0.15 \mathrm{~mm}(\%)$ & Massa $(\%)$ & Sólidos (\%) & $+0.15 \mathrm{~mm}(\%)$ \\
\hline 176 & 99,70 & 39,50 & 7,33 & 7,5 & 75,4 & 72,2 & 92,50 & 38,00 & 1,21 \\
\hline 149 & $103, \infty$ & 45,30 & 7,33 & 10,7 & 75,3 & 60,7 & 89,30 & 43,20 & 1,14 \\
\hline 122 & $101, \infty$ & 50,70 & 7,33 & 12,4 & 72,4 & 49,7 & 87,60 & 48,60 & 0,80 \\
\hline 211 & $120, \infty$ & 39,50 & 7,33 & 9,0 & 75,1 & 68,8 & $91, \infty$ & 37,70 & 1,38 \\
\hline 178 & $124, \infty$ & 45,30 & 7,33 & 11,8 & 72,6 & 56,0 & 88,20 & 43,10 & 0,91 \\
\hline 145 & $121, \infty$ & 50,70 & 7,33 & 13,4 & 74,9 & 50,7 & 86,6 & 48,3 & 0,74 \\
\hline
\end{tabular}

Já a tabela 4 ilustra as eficiências de remoção de finos, de retenção de grossos e a eficiência global obtidas nos respectivos testes.

Tabela 4: Eficiência de peneiramento obtida nos testes com telas de $0.15 \mathrm{~mm}$

\begin{tabular}{|cc|c|c|c|}
\hline Massa (t/h) & Sólidos (\%) & Oersize (\%) & Undersize (\%) & Goba (\%) \\
\hline 99,70 & 39,50 & 84,90 & 97,40 & 96,50 \\
103,00 & 45,30 & 86,10 & 96,60 & 94,90 \\
101,00 & 50,70 & 90,60 & 92,70 & 92,60 \\
120,00 & 39,50 & 82,80 & 97,00 & 96,00 \\
124,00 & 45,30 & 89,00 & 94,50 & 94,10 \\
121,00 & 50,70 & 91,20 & $93, \infty 0$ & 92,80 \\
\hline
\end{tabular}

A figura 4 mostra a eficiência global versus a concentração mássica de sólidos obtida nos testes com a abertura de $0.15 \mathrm{~mm}$.

* Contribuição técnica ao 44ํㅗㄴ Seminário de Redução de Minério de Ferro e Matérias-primas, $15^{\circ}$ Simpósio Brasileiro de Minério de Ferro e $2^{\circ}$ Simpósio Brasileiro de Aglomeração de Minério de Ferro, 15 a 18 de setembro de 2014, Belo Horizonte, MG, Brasil. 


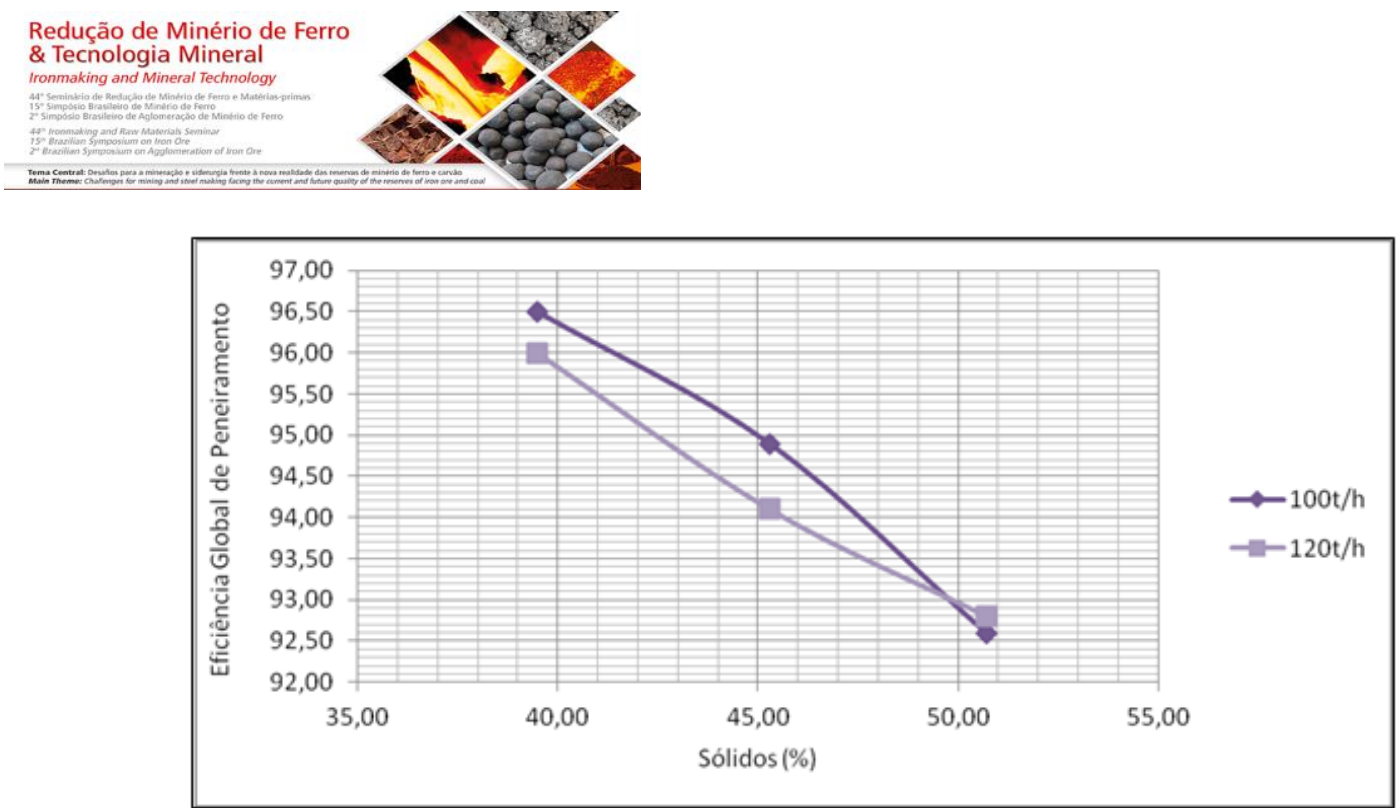

Figura 4: Eficiência global de peneiramento versus concentração mássica de sólidos para os testes realizados com abertura das telas em $0.15 \mathrm{~mm}$.

Em termos de eficiência global, todos os resultados ficaram acima de $90 \%$. O melhor resultado foi obtido com 100 t/h de taxa de alimentação e $40 \%$ de sólidos.

Após a execução de todos os ensaios com a tela de $0.15 \mathrm{~mm}$, foi feita a substituição das mesmas por telas com abertura de $0.18 \mathrm{~mm}$ e em seguida repetiu-se as etapas anteriores.

A tabela 5 apresenta os resultados obtidos para abertura de tela em $0.18 \mathrm{~mm}$ com taxa de alimentação de 100 e 120 t/h. Os percentuais de sólidos também variaram em 40, 45 e $50 \%$ de sólidos.

Tabela 5: Alimentação, oversize e undersize obtidos nos testes com telas de $0.18 \mathrm{~mm}$

\begin{tabular}{|c|c|c|c|c|c|c|c|c|c|}
\hline \multicolumn{4}{|c|}{ Alimentação } & \multicolumn{3}{|c|}{ Oversize } & \multicolumn{3}{|c|}{ Undersize } \\
\hline Vazão (m3h) & Massa $(t / h)$ & Sólidos (\%) & $+0.15 \mathrm{~mm}(\%)$ & Massa $(\%)$ & Sólidos (\%) & $+0.15 \mathrm{~mm}(\%)$ & Massa (\%) & Sólidos (\%) & $+0.15 \mathrm{~mm}(\%)$ \\
\hline 176,00 & 99,70 & 39,50 & 7,33 & 5,30 & 74,10 & 82,00 & 94,80 & 38,50 & 2,41 \\
\hline 149,00 & $103, \infty$ & 45,30 & 7,33 & 6,00 & 74,30 & 78,90 & 94,00 & 44,20 & 2,78 \\
\hline 122,00 & 101,00 & 50,70 & 7,33 & 8,20 & 75,50 & 72,40 & 91,80 & 49,30 & 2,18 \\
\hline 211,00 & 120,00 & 39,50 & 7,33 & 6,20 & 74,50 & 77,70 & 93,80 & 38,30 & 2,38 \\
\hline 178,00 & $124, \infty$ & 45,30 & 7,33 & 7,40 & 74,60 & 76,20 & 92,70 & 43,90 & 2,36 \\
\hline 145,00 & 121,00 & 50,70 & 7,33 & 7,80 & 75,90 & 78,40 & 92,20 & 49,30 & 1,73 \\
\hline
\end{tabular}

Já a tabela 6 ilustra as eficiências de remoção de finos, de retenção de grossos e a eficiência global obtidas nos respectivos testes.

Tabela 6: Eficiência de peneiramento obtida nos testes com telas de $0.18 \mathrm{~mm}$

\begin{tabular}{|cc|c|c|c|}
\hline Massa (t/h) & Sólidos (\%) & Oversize (\%) & Undersize (\%) & Global (\%) \\
\hline 99,70 & 39,50 & 69,10 & 98,80 & 96,60 \\
103,00 & 45,30 & 64,40 & 98,60 & 96,10 \\
101,00 & 50,70 & 72,50 & 97,80 & 96,00 \\
120,00 & 39,50 & 69,60 & 98,40 & 96,30 \\
124,00 & 45,30 & 70,00 & 98,30 & 96,20 \\
121,00 & 50,70 & 78,4 & 97,3 & 96,9 \\
\hline
\end{tabular}

A figura 5 mostra a eficiência global versus a concentração mássica de sólidos obtida nos testes com a abertura de $0.18 \mathrm{~mm}$.

\footnotetext{
* Contribuição técnica ao 44 Seminário de Redução de Minério de Ferro e Matérias-primas, 15ํ Simpósio Brasileiro de Minério de Ferro e $2^{\circ}$ Simpósio Brasileiro de Aglomeração de Minério de Ferro, 15 a 18 de setembro de 2014, Belo Horizonte, MG, Brasil.
} 


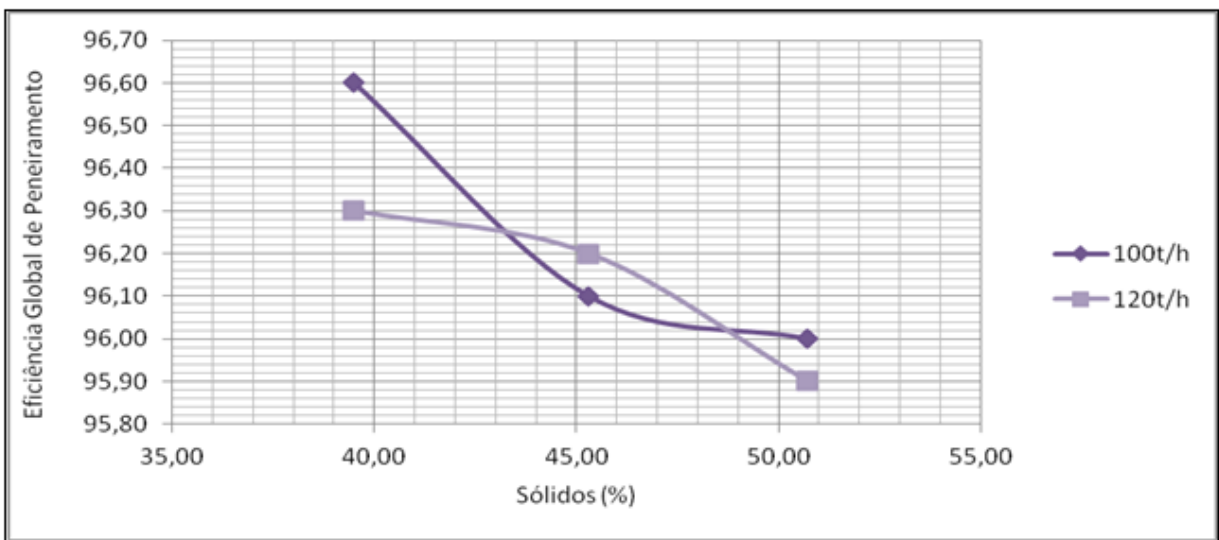

Figura 5: Eficiência global de peneiramento versus concentração mássica de sólidos para os testes realizados com abertura das telas em $0.18 \mathrm{~mm}$.

Todos os testes com abertura de $0.18 \mathrm{~mm}$ apresentaram eficiência global acima de $95.9 \%$. O melhor resultado obtido também foi com 100 t/h com $40 \%$ de sólidos na alimentação da peneira.

A exemplo do que havia ocorrido para os testes com $0.15 \mathrm{~mm}$, a eficiência global de peneiramento também caiu com o aumento do percentual de sólidos e da taxa de alimentação nos testes com abertura de telas em $0.18 \mathrm{~mm}$.

Estes resultados mostram claramente que a capacidade e a eficiência de um peneiramento são variáveis que tem relação inversa.

As figuras 6, 7 e 8 mostram os resultados do percentual da fração retida em $0.15 \mathrm{~mm}$ no undersize das peneiras para as duas aberturas de telas testadas e variações de taxa de alimentação em 100 e 120 t/h.

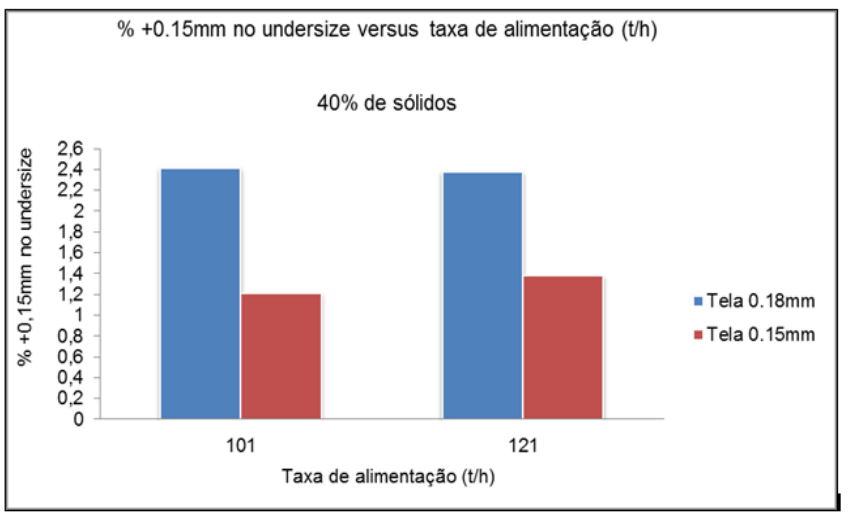

Figura 6: Percentual maior que $0.15 \mathrm{~mm} \times$ taxa de alimentação para $40 \%$ de sólidos

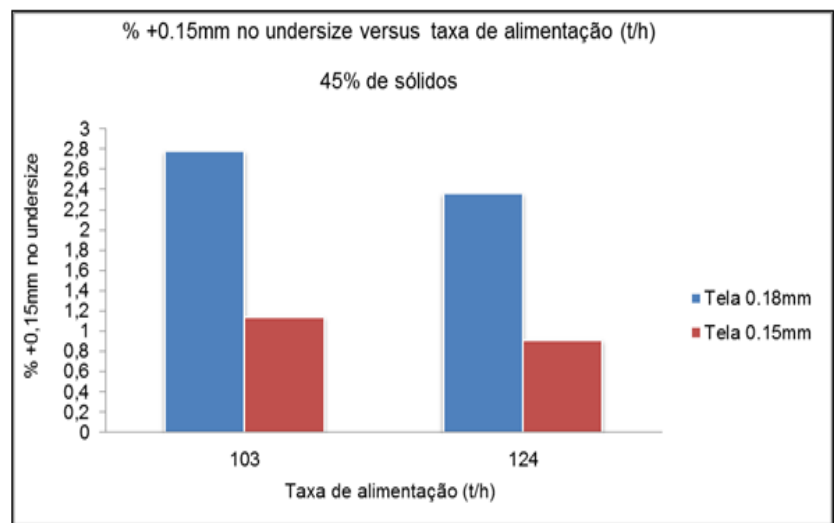

Figura 7: Percentual maior que $0.15 \mathrm{~mm} \times$ taxa de alimentação para $45 \%$ de sólidos.

* Contribuição técnica ao 44ํㅗㄴ Seminário de Redução de Minério de Ferro e Matérias-primas, 15ํ Simpósio Brasileiro de Minério de Ferro e $2^{\circ}$ Simpósio Brasileiro de Aglomeração de Minério de Ferro, 15 a 18 de setembro de 2014, Belo Horizonte, MG, Brasil. 


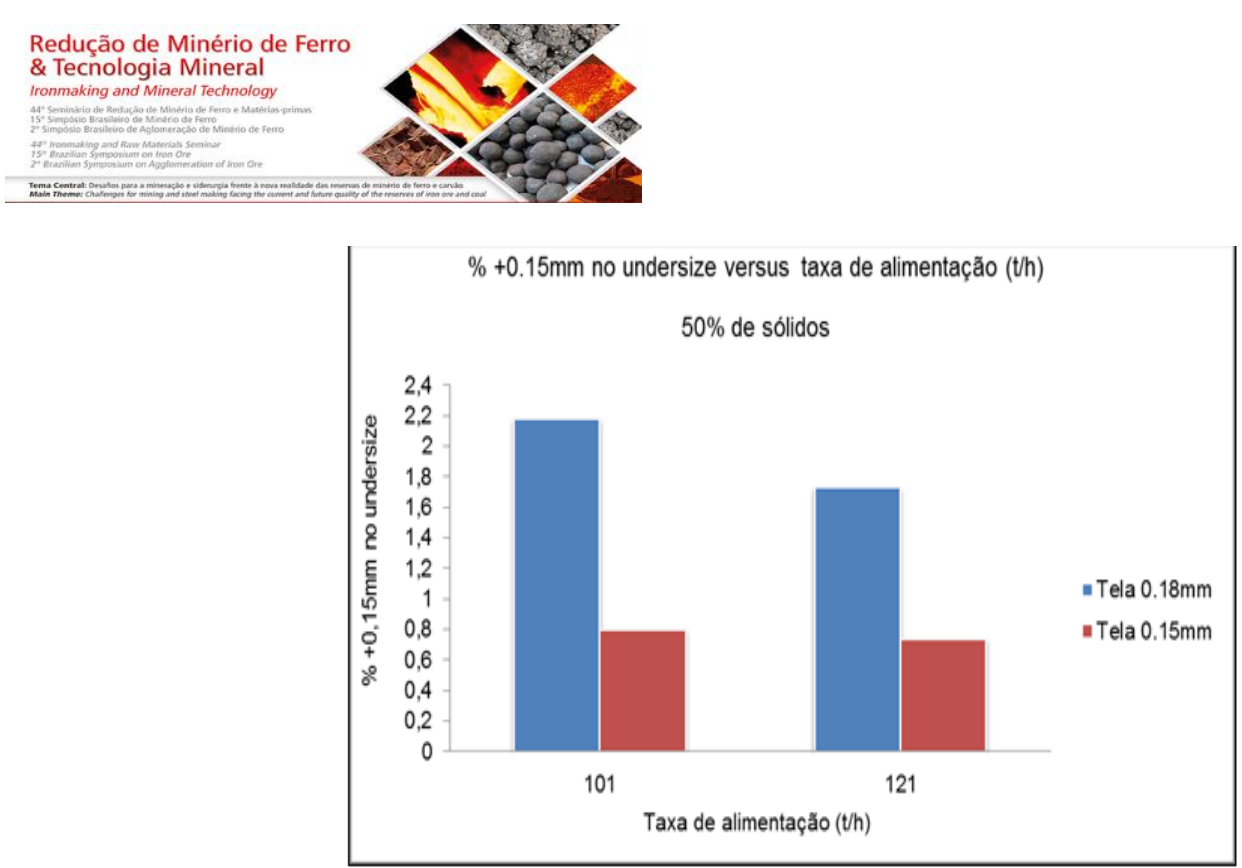

Figura 8: Percentual maior que $0.15 \mathrm{~mm} \times$ taxa de alimentação para $50 \%$ de sólidos.

$\mathrm{Na}$ segunda etapa do trabalho, realizou-se os testes industriais, onde as peneiras foram instaladas antes da flotação em colunas cujo objetivo era minimizar o percentual retido em $0.15 \mathrm{~mm}$ que alimentava o circuito.

Os parâmetros utilizados nos testes industriais foram: telas com abertura de $0.18 \mathrm{~mm}, 40 \%$ de sólidos e taxa de alimentação de $100 \mathrm{t} / \mathrm{h}$ por peneira.

Neste circuito utilizaram-se oito peneiras modelo StackSizer e a figura 9 apresenta os resultados da fração retida em $0.15 \mathrm{~mm}$ na alimentação e o percentual de $\mathrm{SiO}_{2}$ no concentrado da flotação.

$\%+0.15 \mathrm{~mm}$ na alimentação da flotação e \%SiO2 no concentrado antes e depois dos testes

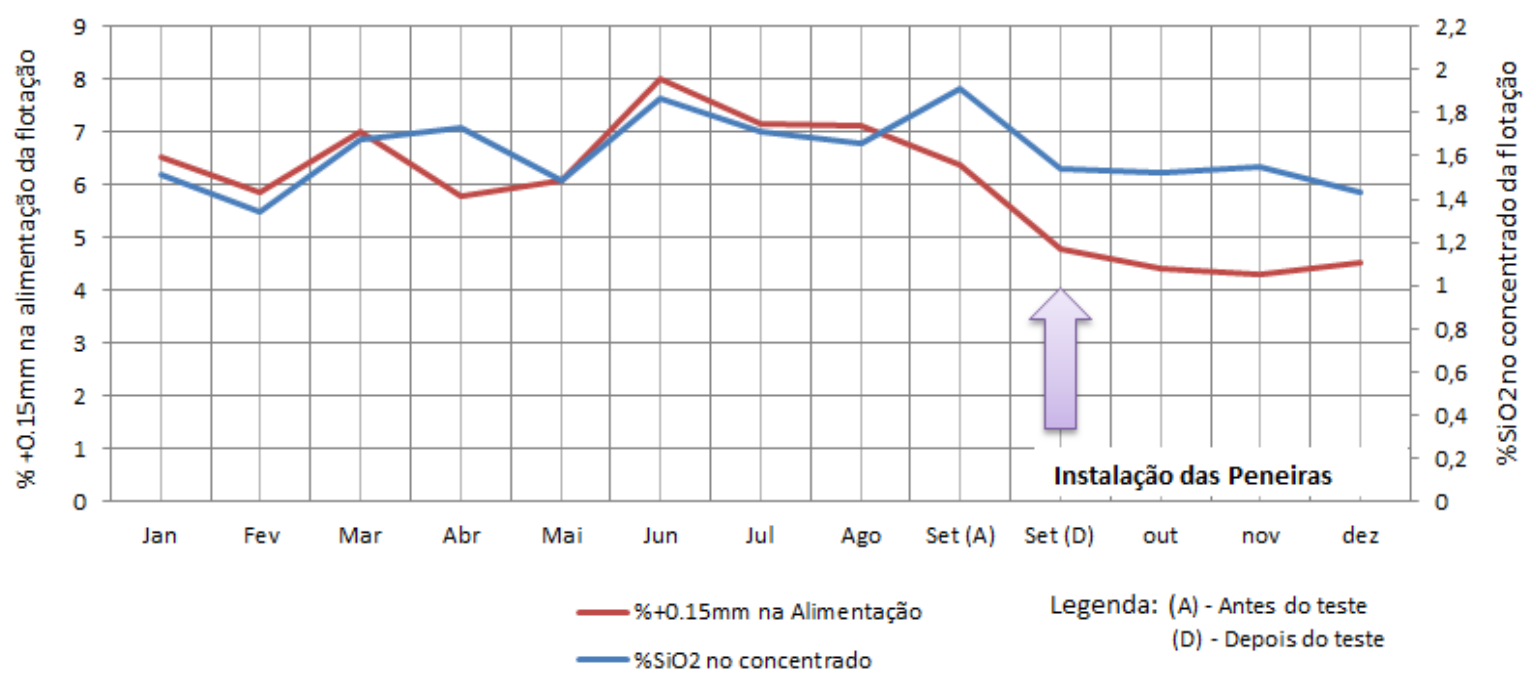

Figura 9: Percentual retido em $0.15 \mathrm{~mm}$ na alimentação da flotação e percentual de sílica no concentrado antes e depois dos testes.

De acordo com a figura 9, observa-se que após a realização dos testes, executados na segunda metade de setembro, houve uma queda no percentual retido em $0.15 \mathrm{~mm}$ da alimentação da flotação de 6,65 para $4,50 \%$.

Outro parâmetro que pode ser observado no gráfico é o teor de sílica no concentrado da flotação, onde a média dos testes antes da utilização das peneiras era $1,65 \%$ e após os testes passou para $1,51 \%$.

Em termos de teor de ferro, a média do concentrado antes dos testes era $68,19 \%$ e nos meses seguintes passou a ser $68,37 \%$.

* Contribuição técnica ao 44 Seminário de Redução de Minério de Ferro e Matérias-primas,

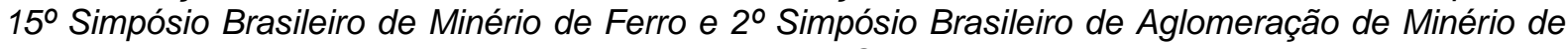
Ferro, 15 a 18 de setembro de 2014, Belo Horizonte, MG, Brasil. 
Foi feita uma simulação do processamento desta polpa num circuito de ciclones para efeito comparativo com os resultados obtidos com as peneiras de alta frequência.

Os parâmetros utilizados na simulação foram os seguintes: ciclone de 26", fundo plano, com inlet de $60 \mathrm{pol}^{2}$, vórtex finder e ápex de 10 e 3,5 polegadas respectivamente e pressão de entrada de $0,60 \mathrm{kgf} / \mathrm{cm}^{2}$.

Os resultados da simulação estão apresentados na tabela 7.

Tabela 7: Resultados obtidos a partir da simulação do processamento da polpa utilizada nos testes no circuito de ciclones

\begin{tabular}{|c|c|c|c|c|c|c|c|c|c|c|}
\hline \multirow{2}{*}{$\begin{array}{c}\text { Tamanho } \\
\text { (micron) }\end{array}$} & \multicolumn{3}{|c|}{ ALIMENTAÇÃO } & \multicolumn{3}{c|}{ OVERFLOW } & \multicolumn{3}{c|}{ UNDERFLOW } \\
\cline { 2 - 11 } & PASS (\%) & IND (\%) & t/h & PASS (\%) & IND (\%) & t/h & PASS (\%) & IND (\%) & t/h \\
para underflow
\end{tabular}

Conforme a simulação realizada, o material acima de 150 micrometros é o contaminante do processo, neste caso temos apenas $3 \%$ retido em 300 micrometros. Em função deste baixo percentual a simulação mostra que não há ganhos com a utilização de ciclones.

\section{CONCLUSÃO}

De acordo com resultados obtidos nos testes em escala laboratorial e em escala industrial, conclui-se que a peneira de alta frequência é uma boa alternativa para classificação de materiais finos $(<1 \mathrm{~mm})$.

O escalpe da fração $0.15 \mathrm{~mm}$ da alimentação da flotação de $6,65 \%$ para 4,50\% proporcionou uma redução no teor de sílica de $67 \%$ e elevação no teor de ferro de $0,25 \%$, melhorando a qualidade do concentrado da flotação.

Além das peneiras apresentarem eficiência superior aos ciclones, elas são menos sensíveis a variações de processo em geral. Logicamente que para cada caso deverá ser realizado um comparativo entre custo e benefício, já que o dispêndio necessário para aquisição das peneiras são maiores que para os ciclones.

\section{Agradecimentos}

Os autores deste trabalho agradecem em especial ao Lucas Gomes, Marcelo Calixto, Gilberto Santiago, Geovar Domingues, Alisson Zacarias, Fábio Tonelli, Rogério São José, Wanderson Campos, Pedro Davisson, Steven Valine, Laercio Albuquerque, José Aurélio Medeiros da Luz, Companhia Derrick e por todos que contribuíram para realização dos testes e do texto.

\section{REFERÊNCIAS}

1 Ahmed N, Jameson. The effect of bubble size on the rate of flotation fine particles. Int.J.of Mineral Processing, 1985; (14): 195-215.

2 Albuquerque, L.G., Valine, S. B., Wheeler, J.E., Fine Sizing with The Derrick $\AA^{\circledR}$ Stack Sizer ${ }^{\text {TM }}$ Screen. Derrick Corporation, 590 Duke Road, Buffalo, NY 14225, USA 2008

\footnotetext{
* Contribuição técnica ao $44^{\circ}$ Seminário de Redução de Minério de Ferro e Matérias-primas, 15ํ Simpósio Brasileiro de Minério de Ferro e $2^{\circ}$ Simpósio Brasileiro de Aglomeração de Minério de Ferro, 15 a 18 de setembro de 2014, Belo Horizonte, MG, Brasil.
} 
3 Albuquerque LG, Jobe W, Valine SB, Ganahl B. Derrick Corporation, USA and Godofredo Barrios Goldex S.A., Peru - Application of high frequency screens in closing grinding circuits, 2009.

4 Amorim IBSF. Influência do tamanho das partículas na flotação. Trabalho de Conclusão de Curso apresentado à Universidade Federal de Goiás, 2013.

5 Carvalho WR, Martins J. Análise do efeito da granulometria da sílica na flotação convencional reversa de minério de ferro. Revista da Escola de Minas, 2005

6 Chaves AP, et al. Teoria e prática do tratamento de minério, volume 1, Signus, São Paulo. 1996.

7 Hernániz F, Calero M. Froth flotation: kinetic models based on chemical analogy. Chem. Eng.and Process, 2001; (40): 269-275.

8 Masini, et al, Caracterização, cominuição e classificação de minérios, In: tratamento de minérios e hidrometalurgia, ITEP, Recife 1980.

9 Vieira AM. Efeito da Granulometria na Flotação de Quartzo. Tese de doutorado, 2005.

* Contribuição técnica ao $44^{\circ}$ Seminário de Redução de Minério de Ferro e Matérias-primas, 15ํ Simpósio Brasileiro de Minério de Ferro e $2^{\circ}$ Simpósio Brasileiro de Aglomeração de Minério de Ferro, 15 a 18 de setembro de 2014, Belo Horizonte, MG, Brasil. 